\title{
The Aims and Structures of Ecological Research Programs
}

William C. Bausman

This is a post-peer review, but pre-production version of this paper, which has been accepted for publication for Philosophical Topics 47(1), special issue on the Philosophy of Ecology, edited by Jay Odenbaugh and Stefan Linquist

\begin{abstract}
:
Neutral Theory is controversial in ecology. Ecologists and philosophers have diagnosed the source of the controversy as: its false assumption that individuals in different species within the same trophic level are ecologically equivalent, its conflict with Competition Theory and the adaptation of species, its role as a null hypothesis, and as a Lakatosian research programme. In this paper, I show why we should instead understand the conflict at the level of research programs which involve more than theory. The Neutralist and Competitionist research programs borrow and construct theories, models, and experiments for various aims and given their home ecological systems. I present a holistic and pragmatic view of the controversy that foregrounds the interrelation between many kinds of practices and decisions in ecological research.
\end{abstract}

\section{Introduction}

Stephen Hubbell's 2001 The Unified Neutral Theory of Biodiversity and Biogeography instigated a controversy among community ecologists. This paper investigates how we should understand what is controversial about Neutral Theory. I aim to identify the root of the controversy to illuminate the organization of scientific research. Neutral Theory is neutral because it idealizes away any differences between individuals of any species and hypothesizes that chance and history structure communities. Hubbell developed Neutral Theory to oppose the focus on the roles of competition between species in shaping ecological communities. Ecologists have understood the controversy in a variety of ways, but they have centered on the neutrality assumption and its conflict with Competition Theory. 
After discussing the controversy in the literature, I argue against focusing on the propositions of Neutral Theory because this ignores how ecologists use and develop theories further. I take David Tilman's Resource Ratio Theory as an example of a Competition Theory and I show how both Hubbell and Tilman intertwined their theoretical program with an empirical program to further their aims. Drawing on the history of Hubbell and Tilman's programs, I build towards a holistic and pragmatic understanding of the conflicts between Neutralist and Competitionist Research Programs. Research programs coordinate theorizing, modeling, and experimenting to respond productively to however the world responds to their probing. Theory bias leads us to either analyze static theories or foreground theorizing and backgrounding other practices, both of which limit the ways scholars of science and scientists themselves see controversies in science. Neutral Theory is controversial in part because it assumes something that is false and in opposition to other accepted theories. But stepping back, this false assumption plays a crucial role in structuring the Neutralist Research Program and ties the theorizing and modeling to the empirical study of tropical rain forests. Competitionists organize their research programs to investigate the world in other ways, for other aims, and based on other parts of the world. The controversy stems from these alternative ways of organizing overlapping research.

\section{The Neutralist-Competitionist Controversy}

Hubbell's Neutral Theory hypothesizes that three processes structure single trophic level community abundance patterns: drift (random birth and death), dispersal, and speciation. It assumes that all individuals, regardless of species, are functionally equivalent in how these processes affect them. Neutral Theory is formalized into mathematical models and used to make predictions about patterns tracking the number of species and individuals across space and time. 
To be controversial, a thing must show promise and it must provoke conflict. Ecologists responded to Hubbell's work on Neutral Theory in a variety of ways. Hubbell showed that neutral models describe the abundance patterns of trees in tropical forests especially well. Many ecologists performed normal scientific applications of the neutral model to a variety of communities from rotifers (Beres, Wallace, and Segers 2005), to grasslands (Harpole and Tilman 2006), to birds (McGill 2003). These comparisons yielded a range of model fits, with some dramatic claims to have refuted the theory with coral reef data (Dornelas, Connolly, and Hughes 2006).

In targeting the controversy, some focus on a tension between the falsity of the neutrality assumption and its empirical success. "This neutral theory has already sparked some controversy in the literature and has inspired many studies. Although the theory's predictions seem consistent with much empirical data, how can such a theory, with assumptions that are so obviously wrong, be useful?” (de Mazancourt 2001, 1772). “Hubbell’s ‘Unified Neutral Theory of Biodiversity and Biogeography' (UNTB) has generated much controversy about both the realism of its assumptions and how well it describes the species abundance dynamics in real communities" (Mutshinda, O'Hara, and Woiwod 2008, 340). Not everyone expects false models to be useful.

Others focus on the conflict between what Neutral Theory and Competition Theory hypothesize about the world. According to Competition Theory, patterns of abundance and diversity result from the ongoing war between differentially adapted species competing for limited resources, the most abundance species being the best adapted to the given resources (Weber 1999). Several authors pointed out the conflict between Hubbell and Darwin's emphasis on adaptive divergence between species (Alonso, Etienne, and McKane 2006, Leigh 2007). Neutral Theory encouraged other ecologists to update and repackage Competition Theory (Chase 
and Leibold 2003).

Still other see the controversy with Competition Theory as methodological. One way of framing the controversy portrays Neutral Theory as a statistical null hypothesis (Yu, Terborgh, and Potts 1998, Linquist et al. 2015, Bausman and Halina 2018, Odenbaugh forthcoming). Hubbell himself slipped into this at times, "At the very least, neutral theory will remain a rich source of quantitative null hypotheses about the dynamics of ecological communities across multiple spatial and temporal scales" (Hubbell 2006, 1338). Graham Bell distinguished between the strong and weak versions or uses of neutral models (Bell 2001). The Weak interpretation holds that neutral models supply the null hypothesis for testing for whether ecologists should accept Competition Theory's hypotheses about communities. When Neutral Theory supplies the null hypothesis in this way, they must neutral hypotheses before accepting competition hypotheses. As this is a strong position to be in, this threatens Competition Theory and its users. The Strong interpretation of Neutral Theory holds that neutral models supply alternative causal hypotheses on a par with those from competition models and cannot undermine the causal relevance of competition. Here Neutral Theory is in conflict only with the often-assumed greater strength of competition over drift, dispersal, and speciation.

Another response to the Neutral Theory emphasizes that both it and Competition Theory should continue to develop as research programs (Chave 2004). Neutralists looked forward to what could yet be done with Neutral Theory (Alonso, Etienne, and McKane 2006, Rosindell, Hubbell, and Etienne 2011). Others proposed syntheses of both theories (Vellend 2010). Recently, some ecologists even argued for why Neutral Theory is at the center of a degenerate Lakatosian research programme while Competition Theory's programme is progressive (Ale et al. 2019). 
While this controversy continues to shift, Neutral Theory continues to occupy ecologists with normal science and has earned a place in community ecology textbooks (Morin 2009). To begin to understand more deeply, let me introduce Neutral Theory and Competition Theory in detail.

\section{Neutral Theory}

The basic Neutral Theory Hubbell presents in his 2001 book works as follows. Neutral Theory is a theory of single trophic level patterns such as relative species abundance distributions (SADs), how SADs vary in space and time, and species-area curves. Focusing on single trophic levels removes interactions such as predation and parasitism. SADs record the number of individuals in each species in a community. Neutral Theory hypothesizes that abundance patterns result from just three processes acting on standing abundance: drift, dispersal, and speciation. It assumes saturation, that communities maintain a constant size, and neutrality, that all individuals, regardless of species, have the same ecological rates. Under these assumptions individuals have identical chances of dying, giving birth, immigrating, and being a member of the new species and that individuals compete as equals for space, interspecific competition being no different from intraspecific competition. Neutral Theory models community dynamics with a local community which receives immigrants from a metacommunity. Under drift alone, the local community diversity will decrease over time as species go locally extinct. In the local community, dispersal introduces migrants of novel species from the metacommunity and balances drift. In the metacommunity, speciation balances drift. The models are stochastic, individual-based models with 3 free parameters: local community size, immigration rate, and biodiversity number (a function of metacommunity size and speciation rate). 
Neutral Theory carries on several traditions of theorizing in ecology and other biological sciences. ${ }^{1}$ First, tropical forest ecology explored how lottery processes structure tropical forests (Connell 1978) Hubbell's first two papers on the ancestor of Neutral Theory are tropical forest ecology papers (Hubbell 1979, Hubbell and Foster 1986). Second, MacArthur and Wilson's Theory of Island Biogeography modeled species richness and species-area relations as the balance of immigration and extinction (MacArthur and Wilson 1963, 1967). Island Biogeography remains a foundational theory in community ecology. Third, Hubbell drew results and inspiration from the Neutral Theory of molecular evolution (Kimura 1968, Caswell 1976) and the MBL model of clade diversity (Raup and Gould 1974), both of which use analogous processes (Hubbell 1979, 2005). Graham Bell also published on neutral models when Hubbell was preparing his book (Bell 2000, 2001).

\section{Competition Theory}

Competition Theory is a broader class of theories in ecology that all model the effects of interspecific competition between differentially adapted species. One exemplar of a competition theory is David Tilman's Resource Ratio Theory and I will use this as an exemplar (Tilman 1982). Resource Ratio, also called $R^{*}$ "R-Star" Theory, is a mechanistic model of competition between species for limited resources. $\mathrm{R}^{*}$ Theory targets community abundance data and resource-species correlations. $\mathrm{R}^{*}$ Theory assumes that each species has a minimum level of a resource (the $\mathrm{R}^{*}$ Value) below which it cannot maintain a constant population size. The theory then hypothesizes that when two species compete for a limited resource, the species with the smaller $\mathrm{R}^{*}$ value for that resource will exclude the other. In the simplest case, 2 species will

\footnotetext{
${ }^{1}$ An extended analysis of the origins of neutral theory is found in (Bausman 2016, Chs. $1 \& 2$ ).
} 
coexist if there are for 2 limiting resources and neither has smaller $\mathrm{R}^{*}$ values for both resources. $\mathrm{R}^{*}$ Theory models deterministic, population-level models with 2 free parameters for the population size and resource level of every resource-species pair modeled.

There is a long tradition of theorizing based on interspecific competition theory in ecology. Darwin's struggle for existence is about the competitive interactions of species with each other and their environments in evolution. The competitive exclusion principle has been an organizing principle of competition theory (Weber 1999). It states that if species in the same region utilize too similar of resources, one will come to exclude the other. Grinnell proposed this principle for field work on birds (Grinnell 1904) and Gause for laboratory experiments on paramecium (Gause 1932). Competitive exclusion is also stated using the concept of the niche and Niche Theory is another name for the approach. The modern niche concept includes the environmental conditions and interactions with other animals from both Grinnell (Grinnell 1917) and Elton (Elton 1927). Hutchinson formalized the notions of the fundamental and realized niches (Hutchinson 1957) and this led to a tradition in understanding coexistence in terms of the limiting similarity of niches (MacArthur and Levins 1967). Lotka and Volterra developed simple competition-based models (Lotka 1925, Volterra 1926). Robert MacArthur developed their approach further into a theory of the relationship between growth rates and resource levels (MacArthur 1972). $\mathrm{R}^{*}$ Theory extends this line of development. Jared Diamond proposed the concept of assembly rules to explain co-occurrence patterns of birds in an archipelago based on interspecific competition and niches (Diamond 1975).

Neutral Theory and Competition Theory are both theories of the diversity and abundance of ecological communities, but they target overlapping patterns. Both aim to predict and explain the number of species for example, but Neutral Theory is targeted at biogeographic patterns of 
how relative abundances vary in space and time whereas Competition Theory is targeted at the correlations between resource and species abundances. Put another way, Neutral Theory is more interested in larger biogeographic scale patterns while Competition Theory is more interested in local landscape scale patterns. When they both target SADs, their predictions need not be distinct depending on the details of the models. This produces an underdetermination of theory by data problem (Purves and Pacala 2005). However, the theories are not strongly underdetermined but make different predictions for other patterns (McGill et al. 2007).

\section{How Not to Understand the Controversy}

There are four temping ways to understand the Neutralist-Competitionist Controversy in ecology that we should resist. First, Neutral Theory is not controversial because ecologists know its neutrality assumption is false. The neutrality assumption was a strong early target of criticism. As the editors noted in their introduction to a special issue of Ecology focused on Neutral Theory, "Most ecologists regard the assumption of all species being equivalent as highly unrealistic..." (Holyoak, Loreau, and Strong Jr 2006). Some still see a tension between empirical success and false assumptions. But neutrality is just one assumption in a discipline with many idealizations and abstractions. Ecologists love to quote George Box's "All models are false, some are useful" (Box and Draper 1987). Different communities satisfy neutrality to different degrees. The important question is the degree to which species differences matter to patterns of abundance, which is just what Hubbell asked. That species differ is obvious; that these differences are responsible is not. Many ecologists believe that they are responsible because of the widely accepted empirical support for Competition Theory and the importance of natural selection in evolutionary theory. Answering this question means in part measuring the size of the 
community, the size of the surrounding metacommunity, the dispersal rate from metacommunity to local community, and speciation rate in metacommunity. And this is a major departure from the dominant way of investigating communities. Competition Theory explains coexistence through hypothesizing species differences and its research strategy recommends that coexisting species need to be investigated until a relevant difference in how they utilize limiting resources is found (Weber 1999).

Second, while the conflict involves Competition Theory, it is not a conflict at level of scientific Theory. The theories conflict with each because they hypothesize that different processes are responsible for the observed patterns of abundance. However, this is not the same opposition found in classic cases of theory choice such as the Geocentric vs. Heliocentric models of the solar system. Here, we cannot reconcile the two models. But we can with Neutral Theory and Competition Theory so long as we assume neither is complete. Drift, dispersal, speciation, and interspecific competition can all influence abundance patterns at different times or in different degrees at the same time. Despite the rhetoric of the controversy, ecologists recognize that all four processes change abundance patterns.

Mark Vellend developed The Theory of Ecological Communities has a theoretical unification of Neutral Theory with Competition Theory (Vellend 2010, 2016). Peter Chesson's Coexistence Theory also produces Neutral Theory and R* Theory as special cases (Chesson 2000). Community ecologists address what John Beatty calls a Relative Significance issue (Beatty 1997). They want to determine the relative significance of the processes represented in multiple theories within a domain, in this case drift, dispersal, speciation, and interspecific competition (Vellend et al. 2014). That Neutral Theory and R* Theory persist through these proposals for theoretical unification suggests that both these and the many other partial theories 
and models in community ecology are each useful for different purposes. If they feel challenged by Neutral Theory, it is because ecologists hoped that interspecific competition was always the most dominant process. ${ }^{2}$ But this is an empirical question.

Third, the Neutral Theory is not primarily in conflict with Competition Theory because Neutral Theory supplies the appropriate null hypothesis for testing Competition Theory. The history of "null hypotheses" in ecology is a source of tension for Neutral Theory. But Neutral Theory is not used in the debate to supply null hypotheses as is portrayed.

The Null Model Wars raged through the 1970s and 80s. Hubbell put himself into this history when he names his theory "neutral" and said it played the role of a "null hypothesis". The Null Model Wars occurred between Jared Diamond and Michael Gilpin on one side and Daniel Simberloff, Edward Connor, and Don Strong on the other side. Jared Diamond argued that cooccurrence data for birds on islands in Melanesia was evidence for the adaptation and interspecific competition of the birds and for their ability to resist invaders (Diamond 1975). Connor and Simberloff responded with a methodological challenge: to infer interspecific competition is responsible for a particular pattern, you need to first "falsify a null hypothesis" that the patterns are rather due to chance colonization (Connor and Simberloff 1979, Strong 1980). This debate raged back and forth through many volleys but had died down by the late 1980s, though the latest round happened only in 2013-15 (Connor, Collins, and Simberloff 2013, 2015, Diamond, Pimm, and Sanderson 2015, Odenbaugh forthcoming).

The Null Model Wars have many lessons for many people. Connor, Simberloff, and later Strong's Popperian justification and misuse of statistical "null hypothesis" language rightly drew

\footnotetext{
${ }^{2}$ One reason for desiring the importance of competition is that it would support the Balance of Nature (Egerton 1973). See (Simberloff 1984, 2014) for an elaboration of this argument.
} 
criticism (Diamond and Gilpin 1982, Quinn and Dunham 1983, Sloep 1986, Bausman and Halina 2018). But they raised the standards of evidence for a hypothesis through testing "null hypotheses" through promoting an important new methodology (Gotelli and Graves 1996) and promoted processes chancy and historical processes. Connor, Simberloff, and Strong at different times presented their null models as only statistical randomizations of existing data and as alternative causal models based on dispersal and colonization. The latter tied them to the influence of MacArthur and Wilson's Theory of Island Biogeography and its focus on dispersal and colonization (MacArthur and Wilson 1967).

Hubbell made clear he was on the side of the null modelers. He shared reviewers' comments on papers he published before his 2001 book and they show this was not lost on other ecologists, e.g. "Ecology is not ready for yet another null model of community assembly. Let sleeping dogs lie." (Hubbell 2008, 145).

Bell saw early that the implications of the reemergence and empirical success of neutral models in ecology depend on their interpretation and use (Bell 2001). Both Weak and Strong uses create tension between Neutral Theory and Competition Theory, but so do in different ways. The Weak use of a neutral model is as a null hypothesis for investigating abundance patterns. Here a neutral model, null with respect to interspecific competition, is used in conjunction with a competition-based model to evaluate whether competition is necessary to explain some data. If the neutral model fits the data well-enough, then invoking competition is unnecessary and so unwarranted. With the Weak use, Neutral Theory challenges Competition Theory by undermining its hypotheses that involve competition. The general threat is that the empirical success of neutral models could show that explaining abundance patterns with competition is never warranted. This use is weak because it makes no assumptions about the relationship 
between neutral models and the systems modeled, and it also cannot be used to infer any positive support for a hypothesis that invokes neutral drift, dispersal, and speciation. The Strong use of Neutral Theory is as a theory of community ecology equal in standing to Competition Theory, drift, dispersal, speciation, and competition all taken to be processes causally relevant to abundance patterns. With the Strong use, Neutral Theory challenges Competition Theory by undermining the importance and strength of interspecific competition on abundance patterns. This use is strong because support for Neutral Theory's assumptions and the empirical success of neutral models gives evidence for drift, dispersal, and speciation being important processes structuring abundance patterns.

Ecologists have used Neutral Theory in the Weak way, but it is not the primary use. When ecologists draw conclusions about the role of neutral processes from neutral models, they adopt the Strong use. And while they often use the rhetoric of "null hypotheses", their actual reasoning does not use statistical null hypothesis testing because they do not employ of statistical hypothesis in an experiment (Bausman and Halina 2018). One sign of this is the fact that predictions of relative abundances derived from Neutral Theory and Competition Theory are not necessarily distinct, making experiments unable to distinguish between them (Sloep 1986, Purves and Pacala 2005, Linquist et al. 2015).

In practice all ecologists including neutralists that interspecific competition is a potential cause affecting abundance in any given ecological community. In this way Neutral Theory is not used to challenge the core of Competition Theory and the weak, null hypothesis use does not account for the source of the controversy raised by Neutral Theory among ecologists in the way discussed here.

Two articles led by philosophers of ecology have addressed the controversy surrounding 
Neutral Theory. Jay Odenbaugh has argued against the Neutral Theory being "simply a 'null model" "and for interpreting it as a "realistic, explanatory theory". This means that the neutrality assumption is an idealization and that neutral drift, dispersal, and speciation are causally relevant to abundance pattern (Odenbaugh forthcoming). In these points we agree. ${ }^{3}$ Stefan Linquist and colleagues have also addressed the source of the controversy surrounding Neutral Theory (Linquist et al. 2015). Like Odenbaugh, they consider Neutral Theory as both a null hypothesis and an explanatory theory. I agree with their arguments against placing the burden of proof of non-neutral models because neutral models are the "default or null hypothesis". This can neither be justified by an appeal to statistics nor to parsimony. Linquist and colleagues also emphasize the failure of model-fit of neutral models to SADs to provide sufficient evidence for neutral models capturing ecological dynamics. I agree with their philosophical decision to avoid answering whether neutral models are in fact explanatory of any ecological systems and with their call to seek direct support for the assumptions of Neutral Theory. But this paper goes beyond these analyses. As I will argue in the remainder of this paper, I do not agree with Odenbaugh and Linquist and colleagues that this controverys can be understood by only considering the theories and theoretical methods at play.

Forth, having accepted that the tension arises from the relationship with Competition Theory, that it is not a conflict of clashing Theories, and that the Strong use dominates, we

\footnotetext{
${ }^{3}$ But I do not agree that Hubbell "has opted to think of the neutral theory as a 'null hypothesis'. Hubbell writes this way, but his project in his book and his conclusions in articles, e.g. about the importance of neutral dispersal on the BCI SADs based on fits to neutral models (Condit, Chisholm, and Hubbell 2012), show that he uses the Strong use and sees neutral theory as a realistic, explanatory theory. I also do not agree that the choice between Neutral Theory as null hypothesis/model and explanatory theory is exclusive. The Strong and Weak interpretations are rather uses of a theory and model and can be used in one way here and the other way there.
} 
should move to seeing the controversy at the level of research programs. But we should resist understanding the controversy in terms of Lakatosian research programmes. Imre Lakatos improved upon Karl Popper's ideas of falsification to move from static theories to dynamic research programmes (Lakatos 1976). Lakatos built his methodology of scientific research programmes to explain how scientists can rationally continue to work on a theory after they have disconfirmed its hypotheses. Because both Neutral Theory and Competition Theory have produced a series of theories and models and continue to be developed, both fit aspects of research programmes. In this, the shift from static hypothesis testing to dynamic theoretical development is crucial for understanding the controversy and scientific research. Lakatos argued that scientists build programmes around a hard core of theoretical claims which are themselves insufficient to generate predictions and which they must never modify. Scientists generate empirical predictions by adding claims to the auxiliary belt, and it is these claims which they may modify make new predictions. Being interested in the rationality of science, Lakatos distinguished two ways in which theories can change. Progressive programmes tend to make new testable predictions which are confirmed empirically while degenerate programmes do not. However, it is only clear in hindsight whether a programme was progressive because all programmes must persist through degenerate phases before they become progressive and most that end up degenerate had progressive phases.

The first problem is that Lakatos' distinction between the hard core and auxiliary belt is too rigid to capture most methodologies. Instead of a hard core of theoretical claims, I propose to understand the methodologies used in research programs in terms of starting points. Starting points are the sets of processes which the scientists begin with at the origin of the research program. I use "research program" when I am not using Lakatos' specific concept. Another kind 
of relative "starting" point would be the set of processes the scientists begin with at a given stage in the development of the program, which may or may not be the same as the original starting point. By analogy with methodological Adaptationism in evolution, we find methodological Neutralism and Competitionism in ecology. Methodological Adaptationism is the approach to investigating biological systems that takes natural selection as its starting point (modified from (Godfrey-Smith 2001, 337)). ${ }^{4}$ Methodological Neutralism is the approach to investigating ecological communities that takes the set of drift, dispersal, and speciation as its starting point. ${ }^{5}$ Methodological Competitionism is the approach to investigating ecological communities that takes interspecific competition as its starting point.

The Neutralist and Competitionist Research Programs use their starting points to investigate the relative significance of drift, dispersal, speciation, and interspecific competition with two reasoning strategies: Baseline Modeling and Adding Complexity. Baseline modeling is a strategy for apportioning the relative significance of a set processes to a pattern (Bausman 2018). Neutralists use the neutral model as their baseline model and Competitionists use their competition model as their baseline model. The baseline model's outputs are compared with

\footnotetext{
${ }^{4}$ Another way to think about adaptationism uses Elizabeth Lloyd's Logic of Research Questions Framework to frame their research questions (Lloyd 2015). She argues that Adaptationists ask, "What is the function of this trait?". However, The Logic of Research Questions framework is useful for criticizing researchers for failing to investigate all known causes. But it is not useful for distinguishing different methodologies each addressing the same relative significance problem because each methodology asks the same question, "What is the cause of this?", but takes a different approach to answering it. See (Bausman 2019) for the expanded version of this argument.

${ }^{5}$ A recent paper argues that the Neutralist research programme is degenerate (Ale et al. 2019). Beyond uncritically using Lakatos' view, the authors misidentify the hard core of the neutralist programme as the neutrality assumption. They then argue that because Neutralists relax this assumption, the program is degenerate. But their argument does not follow if the hard core is identified as drift, dispersal, and speciation. Moreover, both programs use the same strategies to move beyond their starting points.
} 
abundance curves. To the degree that the baseline model fits the data, the processes represented in the baseline model are responsible for the pattern. And deviations from the baseline expectations are inferred to be caused by the processes left out of the baseline model. Because no model fits all patterns perfectly well, both Neutralists and Competitionists will cite drift, dispersal, speciation, and interspecific competition as responsible to different degrees in different communities. But they will not necessarily agree on the relative significance of processes in particular cases.

Adding Complexity is a strategy for augmenting a theory or model. Poor model fit can also be a sign that either the assumptions of the theory or the formalization of the theory into the model need to be changed. The starting point gives direction to how this should be done. For example, starting with $\mathrm{R}^{*}$ Theory, Tilman developed a stochastic niche theory which incorporated drift into resource competition (Tilman 2004). Ecologists working with Neutral Theory relaxed neutrality and developed a version of the neutral model that included small selective differences between species to reduce the total number of species predicted by the model (Rosindell, Harmon, and Etienne 2015). Because their starting points are complementary and together include all known processes, both research programs develop models which include each process. But they do not necessarily use the modified model in every case going forward and they have not converged on a common set of models.

\section{How to Understand the Controversy}

The second and more fundamental limitation of Lakatos' research programmes is their theory bias; research programmes include only series of theories and methods for changing them. Programs differ is more ways than we can see with theory-biased glasses. Research programs use 
combinations of theories, models, and experiments to turn data into evidence for hypotheses to answer questions. I propose to see the controversy as between the collections of the methodological choices made by the Neutralist and Competitionist research programs.

Some the history of Hubbell and Tilman is useful to understand the epistemic differences between their programs. In 1969, the University of Michigan's Department of Zoology hired Stephen Hubbell fresh from his PhD. Hubbell's lab ran lab experiments investigating competition in chemostats and developed competition-based models. Tilman took his first course in biology from Hubbell. Tilman relates that Hubbell impressed upon the ability for theorists to make progress in ecology (Davis 2004, Sprugel 2015). Hubbell left for the University of Iowa in 1976, where he published several theoretical articles extending competition theory (Hansen and Hubbell 1980, Hsu, Hubbell, and Waltman 1978, Hsu, Hubbell, and Waltman 1977). Tilman stayed at the University of Michigan for his PhD where he continued doing chemostat experiments on algae, attempting to balance two populations by varying two nutrient levels (Tilman 1977). Here he developed MacArthur's approach to competition theory into what would become $\mathrm{R}^{*}$ Theory.

In 1979, Hubbell published his first paper in tropical forest ecology. He had set up and censused a 13.44 hectare dry forest in Costa Rica, the first large scale census of tropical trees (Hubbell 1979). He had also developed the community drift model, based on drift and immigration and applied it to the new abundance data he collected. Then in 1980, Hubbell cofounded the Forest Dynamics Plot (FDP) project at the Smithsonian Tropical Forest Research Institute on Barro Colorado Island (BCI), an island created with the Panama Canal. The project has completely censused a 50-hectare plot of old growth forest in 1982, 1985, and every 5 years since. Later, the BCI FDP became the flagship for the Center for Tropical Forest Science's 
Forest Global Earth Observatory that now includes over 60 plots throughout the tropics. The FDP continues to expand the data it collects. Hubbell published several more papers on the community drift model in the 80s before coming back to it in the mid-90s (Wright and Hubbell 1983, Hubbell and Foster 1986, Hubbell 1995, 1997). All of Hubbell's theoretical articles make use of BCI data, and it was a stated initial goal of the FDP to provide data to measure not only competitive processes but also demographic and dispersal processes (Hubbell and Foster 1982).

The University of Minnesota hired Tilman in 1976. The University of Minnesota is home to the Cedar Creek Ecosystem Science Reserve, a 2,200 hectare reserve acquired by the University first in 1942 and incorporated into the national Long Term Ecological Research Network in 1982 (Reserve n.d.). Cedar Creek maintains 1100 long term experimental plots and 2300 permanent observation plots and many short-term plots. Tilman has been involved with Cedar Creek since at least 1980 and has been its director since 1992. Tilman and others focus the reserve on, among many other topics: "mechanisms of plant competition for nutrients and light" and "modeling and ecological theory".

Both Hubbell's Neutralism and Tilman's Competitionism involve theoretical and observational/ experimental sub-programs that are both independent and intertwined. Neither the BCI FDP nor Cedar Creek is limited to investigating features of tropical forests or grasslands that can or may be predicted by Neutral Theory or R* Theory. In fact, both the BCI FDP and Cedar Creek might well have a more significant impact on ecology than either Neutral Theory or $\mathrm{R}^{*}$ Theory. And yet we cannot understand the Neutralist or Competitionist programs without seeing that they are tied to these places and ways of generating data.

A common criticism heard about Neutral Theory is that it is not surprising that it predicts the data from $\mathrm{BCI}$, and other tropical forests, so well because it was after all constructed to 
accommodate its extensive data sets. This concern expresses the rational worry that we need to evaluate a theory on systems beyond those used in its construction to gain evidence. However, three important things moderate this criticism. First, ecologists have compared Neutral Theory with data from many other kinds of communities. Many of them fit very well (in part because fitting SADS is easy), some of them do not. Second, Hubbell's approach to theory building is a priori deductions from ecological principles, not a posteriori inductions from generalizations in data from BCI. And third, the comprehensive studies done in the BCI FDP permit us to evaluate the assumptions of the theory independently from their predictive consequences, an important source of support for theories (Lloyd 1994). Neutrality is approximately satisfied on BCI in the sense that of the 300 species of trees, there are only 12 guilds (Hubbell and Foster 1986, 318). A guild is a group of species that share the same niche and Hubbell and Foster argue that competitionism leads us to expect many, many more adaptive strategies. Independent evaluation of theoretical assumptions come from studying a system independently of the patterns used to test the theory.

Hubbell has in turn criticized $\mathrm{R}^{*}$ Theory for having too many free parameters (Hubbell et al.). Remember $\mathrm{R}^{*}$ Theory requires 2 free parameters (population size and resource concentration) for every resource-species pair. This concern expresses the rational worry that the theory will never be tested to high accuracy for natural systems with large numbers of species like BCI. Measurements of each parameter would take enormous effort and without these independent measurements of the values, the model could fit most data well using parameter fitting procedures.

However, again, this criticism must be tempered. First, tropical rain forests are an extreme case of resource and species diversity. Second, Tilman has confirmed R* Theory's 
predictions using simple chemostat experiments. And third, Tilman and others can measure the values of $\mathrm{R}^{*}$ Theory's free parameters in the grassland plots at Cedar Creek and make confirmed predictions. While Neutral Theory's free parameters are about ecological rates, actually measuring dispersal and speciation rates in a way that can be used in the model is not yet possible. We cannot object to extrapolating from simple cases to complex cases in science without living with a vastly reduced scope of science.

Hubbell and Tilman built their programs to satisfy distinct aims. Both study the domain of community ecology and are interested in explaining and predicting biodiversity. However, they differ in several ways. Hubbell is more interested in biogeography and Neutral Theory aims to explain spatial patterns along with abundance patterns using dispersal within a metacommunity. This serves the practical goal of advising in the design of natural preserves and immigration corridors. Tilman aims to explain resource-species correlations along with abundance patterns, something which will always be outside the scope of Neutral Theory. This serves the practical goal of predicting the changes in ranges due to climate change.

To summarize, considered methodologically, we can compare the Neutralist and Competitionist programs on the following dimensions:

\begin{tabular}{|l|l|l|}
\hline & Competitionists & Neutralists \\
\hline Domain & Community Ecology & Community Ecology \\
\hline Aims & $\begin{array}{l}\text { Explaining and Predicting } \\
\text { Biodiversity, } \\
\text { Biogeography } \\
\text { Advise Preserve Design }\end{array}$ & $\begin{array}{l}\text { Explaining and Predicting } \\
\text { Biodiversity, } \\
\text { Resource-Species Correlations } \\
\text { Predict effects of climate } \\
\text { change on ranges }\end{array}$ \\
\hline Home System & BCI Tropical Forest & Cedar Creek Grassland \\
\hline Experimental Strategy & Natural Experiments & Field Experiments \\
\hline Theoretical Starting Point & Drift, Immigration, Speciation & Interspecific Competition \\
\hline Reasoning Strategies & $\begin{array}{l}\text { Baseline Modeling } \\
\text { Adding Complexity }\end{array}$ & $\begin{array}{l}\text { Baseline Modeling } \\
\text { Adding Complexity }\end{array}$ \\
\hline
\end{tabular}


These two programs are integrated units organized and evolving to better suit the aims given the parts of the world investigated. Certain dimensions are foregrounded or backgrounded in different criticisms but criticizing one aspect of a program has repercussions with other aspects because of their mutual support. The controversy between them is not limited to any subset.

We can see that the programs are integrated if we consider why Hubbell conducts natural experiments and Tilman conducts field experiments. Both Hubbell and Tilman began with laboratory experiments investigating patterns of coexistence and abundance. One reason Hubbell might have left is because he wanted to understand Abundance and Coexistence in natural communities and many ecologists believe that laboratory experiments do not generalize very far (Diamond 1986). Studying tropical forests through comparative natural experiments generalizes freely to other natural systems because the systems have not been controlled or simplified. Tilman moved to field experiments, which has a middling ability to generalize to natural communities. Their aim of understanding natural communities is further seen in the generality of both of their theories, neither being limited to particular types of communities such as plants.

One fact facing both of these programs is that interspecific competition is difficult to measure in natural communities because the signal is weak and the background noise is high. In a tropical forest, dispersal and population sizes can be measured and they are known to be important causal factors. In grassland plots, manipulating nutrient ratios and controlling species diversity enables competition to be measured. The starting point of each program comprises the processes easiest to measure in their home system. These simple explanations for the coordination of the programs bring together all the features which a pragmatic understanding of scientific practice and programs sees as important: Scientists use tools and methods to 
investigate aspects of the world for particular aims.

Finally, I want to relate the unity of these programs to several long running divides within ecology. Ecology is a messy discipline in part because of its history and the diversity of the systems it studies. One important division in natural history was between the zoologists and the botanists. The study of marine invertebrates came about during the rise of ecology and fit together with the botanical tradition (Nyhart 2009, Steiner forthcoming 2019). As a broad generalization, ecologists studying animals have emphasized the roles of competition between species, while those studying plants and marine invertebrates inherited from Botany an emphasis on biogeography and the spatial distribution of organisms (Simberloff 1978, 174). ${ }^{6}$ One reason for this divide must be that animals can move while plants cannot, but the reasons must also include historical contingency and education. This fits the Neutralist program, but Tilman also studies plants. This points to another important divide in ecology.

Most natural history involved only observation and comparative analysis. But other areas of biology and science developed experimental techniques for control and manipulation that were brought to ecology in the early 20th century (Inkpen 2017). Experimental ecology inherited from early exemplars such as Gause's on yeast and Park's on flour beetles an emphasis on investigating the effects of competition (Gause 1932, Park 1948). Observational ecology is more open to demographic and dispersal processes.

We can call the third divide Reductionism vs. Emergentism about the organization of ecological research. Reductionism promotes the study of the diversity of nature and all of its particularities. Being fundamentally high-dimensional systems, reductionists investigate

\footnotetext{
${ }^{6}$ I thank Lynn Nyhart for discussing this issue with me. As should be expected, it is actually much more complicated both historically and contemporarily.
} 
communities through studying the biology of particular species and their responses to other species and their environment. Competitionism's Reductionism can be seen in how it explains species coexistence. As Marcel Weber showed in his treatment of Competition Theory, given the competitive exclusion principle, coexistence is a sign of relevant differences between species or differences in resources (Weber 1999). Only local knowledge of the organisms and systems can reveal the relevant differences. Neutralism's Emergentism can be seen in its statistical approach to complex systems. Similarly to how the thermodynamics of gases is studied without reference to the particular of molecules, neutralists ignore species differences in favor of community-level properties like size and connections with other communities. One reason for the stability of Reductionism and Emergentism in ecology is that communities are at an intermediate level of complexity, between the scales at which either approach is best suited (Mittlebach and McGill forthcoming, Ch. 17).

These divides are porous and all programs in ecology mix and match methods from different sides. But these research traditions remain a source of tension in a domain with such methodological diversity.

\section{Conclusion}

How we explain a scientific controversy reveals what we think is important and pressing in science. I have urged us to move beyond looking at only theories. Most research in ecology is short term and fragmented. The Neutralist and Competitionist programs are exceptional in their longevity and comprehensiveness. Their scope is due in large part to being integrated with the BCI FDP and Cedar Creek. These programs and their controversy functions as an exemplar for seeing the coordination of research programs. On a pragmatic understanding of science, the 
controversy is rooted in the partial opposition of Neutralist and Competitionist, and also many other, research programs.

Pragmatism sees the basic unit of analysis for science as: Scientists use tools and methods to investigate aspects of the world for particular aims. Including tools and methods moves beyond the focus on theories and models for representation emphasized most pragmatic accounts (Giere 1998, Odenbaugh 2005, Van Fraassen 2010). Scientists also use instruments for observation and experimentation as well as statistical techniques for generating evidence. Moreover, in scientific research programs, scientists choose and develop tools and techniques to suit their aims given the aspects of the world they are interested in. The pragmatic account of scientific practices is analogous to the better known account of meaning, where people use words to designate things for purposes (Peirce 1868, Morris 1938). Furthermore, it is analogous to how biologists understand organisms: Organisms use traits and behaviors to interact with parts of the environment for purposes.

In an early and influential paper, John Dewey argued against the Reflex Arc concept in Psychology. The Reflex Arc working hypothesis explains actions as a response to a stimulus. Dewey argued that this duality is a remnant of the older duality of sensations and ideas and needs to be replaced by a view where stimulation and response form but one arc within a circuit of behavior unified in its usefulness for the preservation and reproduction of organisms as evolved by natural selection. For Dewey, stimulus and response are coordinated, and this coordination is the normal state of operation for organisms including ourselves.

Thomas Kuhn exhorted an analogous change in our understanding of science (Kuhn 1962). Instead of focusing on the arc of hypothesis and test, he urged the coordination of paradigms towards the goal of puzzle solving as the normal state. But while Kuhn and Lakatos 
moved beyond the hypothesis testing arc, they did not move beyond theorizing and representing. The later move to foregrounding experimentation practices was a useful corrective but was itself an over-correction. The practice turn in the philosophy of science should be pro-theorizing, modeling, and experimenting together (Chang 2014, Waters 2014). And we should aim to understand how these practices are coordinated towards scientific aims in the evolution and ecology of research. 


\section{References}

Ale, Som B, Abdel Halloway, William A Mitchell, and Christopher J Whelan. 2019. "Does God roll dice? Neutrality and determinism in evolutionary ecology." Biology \& Philosophy 34 (1):3.

Alonso, David, Rampal S Etienne, and Alan J McKane. 2006. "The merits of neutral theory." Trends in ecology \& evolution 21 (8):451-457.

Bausman, William C. 2016. "Neutral Theory, Biased World." PhD, Philosophy, University of Minnesota.

Bausman, William C. 2018. "Modeling: Neutral, Null, and Baseline." Philosophy of Science 85 (4):594-616

Bausman, William C. 2019. The Role of Starting Points: How and Why Research Programs Give Order to their Investigation.

Bausman, William, and Marta Halina. 2018. "Not null enough: pseudo-null hypotheses in community ecology and comparative psychology." Biology \& Philosophy 33 (3):30. doi: 10.1007/s10539-018-9640-4.

Beatty, John. 1997. "Why Do Biologists Argue like They Do?" Philosophy of Science 64 (Proceedings):S432-S443.

Bell, Graham. 2000. "The Distribution of Abundance in Neutral Communities." The American Naturalist 155 (5):606-617.

Bell, Graham. 2001. "Neutral Macroecology." Science 293 (5539):2413-2418.

Beres, Karl A., Robert L. Wallace, and Hendrik H. Segers. 2005. "Rotifers and Hubbell's Unified Neutral Theory of Biodiversity And Biogeography." Natural Resource Modeling 18 (3):363-376. doi: doi:10.1111/j.1939-7445.2005.tb00163.x.

Box, George EP, and Norman R Draper. 1987. Empirical model-building and response surfaces: John Wiley \& Sons.

Caswell, Hal. 1976. "Community structure: a neutral model analysis." Ecological monographs 46 (3):327-354.

Chang, Hasok. 2014. "Epistemic activities and systems of practice: Units of analysis in philosophy of science after the practice turn." In Science after the practice turn in the philosophy, history and social studies of science, edited by Léna Soler, Sjoerd Zwart, Michael Lynch and Vincent Israel-Jost, 67-79.

Chase, Jonathan M, and Mathew A Leibold. 2003. Ecological Niches: Linking Classical and Contemporary Approaches. Chicago: University of Chicago Press.

Chave, Jerôme. 2004. "Neutral theory and community ecology." Ecology letters 7 (3):241-253.

Chesson, Peter. 2000. "Mechanisms of maintenance of species diversity." Annual review of Ecology and Systematics:343-366.

Condit, Richard, Ryan A Chisholm, and Stephen P Hubbell. 2012. "Thirty years of forest census at Barro Colorado and the importance of immigration in maintaining diversity." PloS one 7 (11):e49826.

Connell, Joseph H. 1978. "Diversity in tropical rain forests and coral reefs." Science 199 (4335):1302-1310.

Connor, Edward F, Michael D Collins, and Daniel Simberloff. 2013. "The checkered history of checkerboard distributions." Ecology 94 (11):2403-2414. 
Connor, Edward F, Michael D Collins, and Daniel Simberloff. 2015. "The checkered history of checkerboard distributions: reply." Ecology 96 (12):3388-3389.

Connor, Edward F, and Daniel Simberloff. 1979. "The assembly of species communities: chance or competition?" Ecology:1132-1140.

Davis, Tinsley H. 2004. "Biography of David Tilman." Proceedings of the National Academy of Sciences of the United States of America 101 (30):10851-10853. doi: 10.1073/pnas.0404605101.

de Mazancourt, Claire. 2001. "Consequences of Community Drift." Science 293 (5536):1772. doi: $10.1126 /$ science. 1064207.

Diamond, Jared. 1986. "Overview: laboratory experiments, field experiments, and natural experiments." In Community ecology, edited by Jared Diamond and Ted J Case, 3-22. London: Harper \& Row.

Diamond, Jared M. 1975. "Assembly of species communities." In Ecology and evolution of communities, edited by Martin Cody and Jared M Diamond, 342-444. Cambridge, Massachusetts: Harvard University Press.

Diamond, Jared M, and Michael E Gilpin. 1982. "Examination of the "null" model of Connor and Simberloff for species co-occurrences on islands." Oecologia 52 (1):64-74.

Diamond, Jared, Stuart L Pimm, and James G Sanderson. 2015. "The checkered history of checkerboard distributions: comment." Ecology 96 (12):3386-3388.

Dornelas, Maria, Sean R Connolly, and Terence P Hughes. 2006. "Coral reef diversity refutes the neutral theory of biodiversity." Nature 440 (7080):80-82.

Egerton, Frank N. 1973. "Changing concepts of the balance of nature." Quarterly review of biology:322-350.

Elton, Charles S. 1927. Animal ecology: University of Chicago Press.

Gause, Georgii Frantsevich. 1932. "Experimental studies on the struggle for existence I. Mixed population of two species of yeast." Journal of experimental biology 9 (4):389-402.

Giere, Ronald N. 1998. Explaining science: A cognitive approach: University of Chicago Press.

Godfrey-Smith, Peter. 2001. "Three Kinds of Adaptationism." Adaptationism and Optimality:335-357.

Gotelli, Nicholas J, and Gary R Graves. 1996. Null Models in Ecology. Washington DC: Smithsonian Institution Press.

Grinnell, Joseph. 1904. "The origin and distribution of the chest-nut-backed chickadee." The Auk 21 (3):364-382.

Grinnell, Joseph. 1917. "The niche-relationships of the California Thrasher." The Auk:427-433.

Hansen, Stephen R, and Stephen P Hubbell. 1980. "Single-nutrient microbial competition: qualitative agreement between experimental and theoretically forecast outcomes." Science 207 (4438):1491-1493.

Harpole, Stanley W, and David Tilman. 2006. "Non-neutral patterns of species abundance in grassland communities." Ecology Letters 9 (1):15-23.

Holyoak, Keith J, Michel Loreau, and Donald R Strong Jr. 2006. "Neutral Community Ecology." Ecology 87 (6):1368-1369.

Hsu, SB, SP Hubbell, and Paul Waltman. 1978. "A contribution to the theory of competing predators." Ecological Monographs:337-349.

Hsu, Sze-Bi, S Hubbell, and Paul Waltman. 1977. "A mathematical theory for single-nutrient competition in continuous cultures of micro-organisms." SIAM Journal on Applied Mathematics 32 (2):366-383. 
Hubbell, Stephen P. 1979. "Tree Dispersion, Abundance, and Diversity in a Tropical Dry Forest." Science 203 (4387):1299-1309.

Hubbell, Stephen P. 1995. "Towards a theory of biodiversity and biogeography on continuous landscapes." Progress in biometeorology.

Hubbell, Stephen P. 1997. "A unified theory of biogeography and relative species abundance and its application to tropical rain forests and coral reefs." Coral reefs 16 (1):S9-S21.

Hubbell, Stephen P. 2005. "The Neutral Theory of Biodiversity and Biogeography and Stephen Jay Gould." Paleobiology 31 (S2):122-132.

Hubbell, Stephen P. 2006. "Neutral Theory and the Evolution of Ecological Equivalence." Ecology 87 (6):1387-1398.

Hubbell, Stephen P. 2008. "Approaching Ecological Complexity from the Perspective of Symmetric Neutral Theory." In Tropical Forest Community Ecology, edited by Walter Carson and Stefan Schnitzer, 143-159. Chichester, UK: Wiley-Blackwell.

Hubbell, Stephen P, and Robin B Foster. 1982. The Structure and Dynamics of a Tropical Forest: A Demographic Analysis. The University of Iowa: National Science Foundation. Original edition, DEB-8206992.

Hubbell, Stephen P, and Robin B Foster. 1986. "Biology, chance, and history and the structure of tropical rain forest tree communities." In Community ecology, edited by Jared Diamond and Ted J Case, 330. Harper \& Row.

Hubbell, Stephen P, Kyle E Harms, James W Dalling, Robert John, and Joseph B Yavitt.

Hutchinson, George Evelyn. 1957. "Concluding remarks." Cold spring harbor symposium on quantitative biology 22:415-427.

Inkpen, S Andrew. 2017. "Demarcating Nature, Defining Ecology: Creating a Rationale for the Study of Nature's "Primitive Conditions"." Perspectives on Science 25 (3):355-392.

Kimura, Motoo. 1968. "Evolutionary rate at the molecular level." Nature 217 (5129):624-626.

Kuhn, Thomas S. 1962. The structure of scientific revolutions: University of Chicago press.

Lakatos, Imre. 1976. "Falsification and the methodology of scientific research programmes." In The methodology of scientific research programmes: Philosophical Papers, edited by John Worrall and Gregory Currie. Cambridge: Cambridge University Press.

Leigh, Egbert Giles. 2007. "Neutral Theory: a Historical Perspective." Journal of Evolutionary Biology 20 (6):2075-2091.

Linquist, Stefan, Karl Cottenie, Tyler A Elliott, Brent Saylor, Stefan C Kremer, and T Ryan Gregory. 2015. "Applying ecological models to communities of genetic elements: the case of Neutral Theory." Molecular ecology 24 (13):3232-3242.

Lloyd, Elisabeth A. 1994. The Structure and Confirmation of Evolutionary Theory. Princeton: Princeton University Press.

Lloyd, Elisabeth A. 2015. "Adaptationism and the Logic of Research Questions: How to Think Clearly About Evolutionary Causes." Biological Theory:1-20.

Lotka, Alfred J. 1925. Elements of physical biology.

MacArthur, Robert H. 1972. Geographical ecology: patterns in the distribution of species: Princeton University Press.

MacArthur, Robert H, and Edward O Wilson. 1963. "An equilibrium theory of insular zoogeography." Evolution:373-387.

MacArthur, Robert H, and Edward O Wilson. 1967. The theory of island biogeography. Vol. 1: Princeton University Press. 
MacArthur, Robert, and Richard Levins. 1967. "The limiting similarity, convergence, and divergence of coexisting species." The American Naturalist 101 (921):377-385.

McGill, Brian J. 2003. "A test of the unified neutral theory of biodiversity." Nature 422 (6934):881.

McGill, Brian J, Rampal S Etienne, John S Gray, David Alonso, Marti J Anderson, Habtamu Kassa Benecha, Maria Dornelas, Brian J Enquist, Jessica L Green, Fangliang He, Allen H Hurlbert, Anne E Magurran, Pablo A Marquet, Brian A Maurer, Annette Ostling, Candan U Soykan, Karl L Ugland, and Ethan P White. 2007. "Species abundance distributions: moving beyond single prediction theories to integration within an ecological framework." Ecology letters 10 (10):995-1015.

Mittlebach, Gary, and Brian McGill. forthcoming. Community Ecology. 2nd ed: Oxford University Press.

Morin, Peter J. 2009. Community ecology. 2 ed: John Wiley \& Sons.

Morris, Charles William. 1938. "Foundations of the Theory of Signs." In International encyclopedia of unified science, 1-59. Chicago University Press.

Mutshinda, Crispin M., Robert B. O'Hara, and Ian P. Woiwod. 2008. "Species Abundance Dynamics under Neutral Assumptions: A Bayesian Approach to the Controversy." Functional Ecology 22 (2):340-347.

Nyhart, Lynn K. 2009. Modern nature: The rise of the biological perspective in Germany: University of Chicago Press.

Odenbaugh, Jay. 2005. "Idealized, inaccurate but successful: A pragmatic approach to evaluating models in theoretical ecology." Biology and Philosophy 20 (2-3):231-255.

Odenbaugh, Jay. forthcoming. "Neutrality, Niche, and Nulls: Causal Relevance in Ecology." In Philosophical Perspectives on Causal Reasoning in Biology, edited by C. Kenneth Waters and James Woodward. Minneapolis: University of Minnesota Press.

Park, Thomas. 1948. "Experimental studies of interspecies competition. 1. Competition between populations of the flour beetles, Tribolium confusum Duval and Tribolium castaneum Herbst." Ecological monographs 18:265-307.

Peirce, Charles Sanders. 1868. "Some consequences of four incapacities claimed for man." Journal of Speculative Philosophy 2 (1868):140-157.

Purves, Drew W, and Stephen W Pacala. 2005. "Ecological Drift in Niche-Structured Communities: Neutral Pattern Does Not Imply Neutral Process." In Biotic Interactions in the Tropics: Their Role in the Maintenance of Species Diversity, edited by David Burslem, Michelle Pinard and Sue Hartley, 107-138. Cambridge: Cambridge University Press.

Quinn, James F, and Arthur E Dunham. 1983. "On Hypothesis Testing in Ecology and Evolution." The American Naturalist 122 (5):602-617.

Raup, David M, and Stephen Jay Gould. 1974. "Stochastic simulation and evolution of morphology-towards a nomothetic paleontology." Systematic Biology 23 (3):305-322.

Reserve, Cedar Creek Ecosystem Science. n.d. "History Summary of Cedar Creek." accessed 2019.02.13. https://www.cedarcreek.umn.edu/about/history.

Rosindell, James, Luke J Harmon, and Rampal S Etienne. 2015. "Unifying Ecology and Macroevolution with Individual-Based Theory." Ecology letters 18 (5):472-482.

Rosindell, James, Stephen P Hubbell, and Rampal S Etienne. 2011. "The unified neutral theory of biodiversity and biogeography at age ten." Trends in ecology \& evolution 26 (7):340348. 
Simberloff, Daniel. 1978. "Using island biogeographic distributions to determine if colonization is stochastic." The American Naturalist 112 (986):713-726.

Simberloff, Daniel. 1984. "The great god of competition." The Sciences 24 (4):17-22.

Simberloff, Daniel. 2014. "The "balance of nature" —evolution of a panchreston." PLoS Biol 12 (10): 1001963.

Sloep, Peter B. 1986. "Null Hypotheses in Ecology: Towards the Dissolution of a Controversy." PSA: Proceedings of the Biennial Meeting of the Philosophy of Science Association.

Sprugel, Doug. 2015. "G. David Tilman." Ecological Society of America, accessed June 15. http://esa.org/history/tilman-g-d/.

Steiner, Katharina. forthcoming 2019. "The Scientific Fishery: Sampling, Dissecting, and Drawing in the Gulf of Naples." In Why Study Biology by the Sea?, edited by Jane Maienschein, Karl Matlin and Rachel Ankeny.

Strong, Donald R. 1980. "Null Hypotheses in Ecology." Synthese 43 (2):271-285.

Tilman, David. 1977. "Resource Competition between Plankton Algae: An Experimental and Theoretical Approach." Ecology 58 (2):338-348.

Tilman, David. 1982. Resource Competition and Community Structure. Edited by Simon A. Levin and Henry S. Horn, Monographs in Population Biology. Princeton: Princeton University Press.

Tilman, David. 2004. "Niche Tradeoffs, Neutrality, and Community Structure: A Stochastic Theory of Resource Competition, Invasion, and Community Assembly." Proceedings of the National Academy of Sciences of the United States of America 101 (30):10854-10861.

Van Fraassen, Bas C. 2010. Scientific Representation: Paradoxes of Perspective: Oxford University Press.

Vellend, Mark. 2010. "Conceptual Synthesis in Community Ecology." The Quarterly Review of Biology 85 (2):183-206.

Vellend, Mark. 2016. The Theory of Ecological Communities. Edited by Simon A. Levin and Henry S. Horn, Monographs in Population Biology. Princeton: Princeton University Press.

Vellend, Mark, Diane S Srivastava, Kathryn M Anderson, Carissa D Brown, Jill E Jankowski, Elizabeth J Kleynhans, Nathan JB Kraft, Alathea D Letaw, A Andrew M Macdonald, and Janet E Maclean. 2014. "Assessing the relative importance of neutral stochasticity in ecological communities." Oikos 123 (12):1420-1430.

Volterra, Vito. 1926. "Fluctuations in the abundance of a species considered mathematically." Nature 118:558-560.

Waters, C. Kenneth. 2014. "Shifting Attention From Theory to Practice in Philosophy of Biology." In New Directions in the Philosophy of Science, edited by M.C. Galavotti, D. Dieks, W.J. Gonzalez, S. Hartmann, T. Uebel and Marcel Weber, 121-139. Berlin: Springer International Publishing.

Weber, Marcel. 1999. "The aim and structure of ecological theory." Philosophy of Science:7193.

Wright, S Joseph, and Stephen P Hubbell. 1983. "Stochastic extinction and reserve size: a focal species approach." Oikos:466-476.

Yu, Douglas W, John W Terborgh, and Matthew D Potts. 1998. "Can high tree species richness be explained by Hubbell's null model?" Ecology Letters 1 (3):193-199. 